\title{
Dynamic Monitoring and Assessment for Digital Transformation in Higher Education
}

\author{
Supriyono $^{1, *}$ Muhamad Faisal ${ }^{2}$ \\ ${ }^{1,2}$ Department of Informatics Engineering, Faculty of Science and Technology \\ Universitas Islam Negeri Maulana Malik Ibrahim, Malang, Indonesia \\ ${ }^{*}$ Corresponding author. Email: priyono@ti.uin-malang.ac.id
}

\begin{abstract}
The development of information technology applied to college institutions is experiencing rapid growth. Information technology can solve problems faced in educational institutions. Universities are increasing the use of information and digital technologies for improved service, data management, and accurate reporting. Monitoring and assessment are an essential part of college development. The parameters used in monitoring and assessment use a parameter on the strategic plan of the college. The comparative study of the strategic plan is targeted at two universities that have different characteristics, namely public universities and Islamic state universities. The method used in building dynamic monitoring and assessment uses machine learning. Parameters in monitoring and assessment include Tri Dharma Higher Education such as research, education, and community development. Based on these problems can be formulated implementation of dynamic monitoring and assessment for digital transformation in Higher Education as well as prototype models of dynamic monitoring and assessment based on machine learning. The results obtained show that parameter testing yields an average of $78 \%$. This indicates that the level of accuracy using machine learning can implement dynamic monitoring and assessment in digital transformation at higher education.
\end{abstract}

Keywords: Information Technology, Dynamic Monitoring, Assessment, Machine Learning, Higher Education.

\section{INTRODUCTION}

The development of information technology applied to institutions of universities is experiencing considerable development. Along with the era of industrial revolution 4.0, universities should be able to prepare the next generation of a reliable and resilient nation. In scoring qualified graduates, the role of college becomes very vital. With the advancement of higher education teaching reforms, more people are paying attention to the development of more scientific, intelligent, and effective modern campuses [1]. The more measured and targeted the management of education big data, the better the assessment level in universities and vice versa. It was coupled with the development of big data analysis techniques, Cloud technology, sensors, Internet of Things (IoT) based sensors, and big data processing systems that are sufficiently efficient to monitor the manufacturing process. Furthermore, using the hybrid prediction model has better fault prediction accuracy than other models given the sensor data as input. It is expected to support management by improving decision-making and will help prevent unexpected losses caused by faults during the manufacturing process [2].

The development of digital support equipment requires a digital transformation process towards universities is the best. So, it is necessary to be the measurement, full of planning but remain dynamic and prioritize ecosystem collaboration in the design of digital solutions. The development of the industrial revolution era 4.0 makes universities should be able to make a complete contribution to the implementation of digital transformation [3]. In the process of digital transformation, there is standardization in how people's data can be protected and utilized. Digital transformation in universities covers several aspects. Dynamic monitoring and assessment that is expected to bridge the improvement in the development of digital transformation in a college [4].

The digitization strategies should include a more comprehensive focus and propose that enterprise 
architecture management could provide an essential contribution in structuring digitization efforts and that enterprise or knowledge portals could play a role in implementing the strategies investigate the dynamics of higher education funding and the ensuing impact on part-time teaching, staff to student ratios, staff development, research productivity, and hence the perceived quality, using a system dynamics simulation model [5]. The model developed is based on higher education literature in the developing world in general and particular they use the resulting model to review policies on funding and quality in higher education, and ultimately envisage that the model can easily be adapted to higher education in other environments [6].

Digital transformation in the education sector has implied the involvement of sustainable management to adapt to the changes imposed by new technologies. Trends in global research on this topic have been analyzed and studied during the 1986-2019 period. A bibliometric study of 1590 articles from the Scopus database has been applied. The results provided data on the scientific productivity of authors, journals, institutions, and countries that contribute to the development of this research area. The evidence reveals an exponential trend, with a particular interest in the last five years [7].

Digitalization and transition to a new technological structure bring humanity to another level of development. The changing technological structures, industry, and social progress enhance the importance of improving the university development model. The existing management system and infrastructure in universities are often outdated and unable to ensure their competitive and adequate functioning. Hence, the need to improve the processes of using the university infrastructure through digital technology. The composition and range of the resources should also be reviewed and supplemented with new components. the recommendations formulated to improve the university infrastructure using digital technology will make higher education more effective [8]. Lecturer in Indonesia has three activities that must be done, including teaching, research, and community service. Qualified lecturers not only fulfil these three obligations but also work and are more skilled in each of these points. In every point contained in the Tridharma of higher education, as educators, it is also required to face digital transformation where teaching and learning, face-toface teaching and learning can be equal or more effective by utilizing digital technology to be more flexible. The use of digital technology can make teaching and learning more flexible and lead to improved student skills in learning [9].

Universities must be ready for digital transformation, especially in the covid-19 pandemic. Universities need to improve the productive, effective, and efficient development of human resources. Improved service and management at universities can be measured by the level of digital transformation development. The development of the digital campus can increase the level of efficiency and effectiveness in the management of existing business processes in universities. Based on the problem, the following problems can be formulated How is the implementation of dynamic monitoring and assessment for transformation digital, and how are the potential prototype model of dynamic monitoring and assessment use machine learning.

\section{METHODS}

This research is a comparative study with data collection methods through literature reviews, observation, in-depth interviews, and Focus Group Discussion (FGD). The objects in this research are university stakeholders on campus, curriculum and education experts, and students.

In more detail, the methods in this study can be described as follows:

\subsection{Research Location}

The research was conducted in Malang because it has some characteristic similarities, both as an educational city, with multicultural populations of different ethnicities, religions, and backgrounds. Also, these regions have become one of the areas used by Information Communication and Technology.

\subsection{The Subject of Research}

Institutionally, this research subjects consist of Brawijaya University Malang and State Islamic University of Maulana Malik Ibrahim Malang.

\subsection{Data Collection}

In data collection, the following methods will be used:

\subsubsection{Participative Observation}

Researchers will make observations at the location by reviewing the implementation of dynamic monitoring and assessment to mapping the potential for the development of model and prototype dynamic monitoring and assessment.

\subsubsection{In-depth Interview}

In the data collection process, researchers will conduct in-depth interviews with university stakeholders, education experts, and students regarding the implementation of dynamic monitoring and 
assessment and the possible chance to develop dynamic monitoring and assessment in higher university.

\subsubsection{Literature Reviews}

Researchers will collect various references related to dynamic monitoring and assessment in higher university.

\subsubsection{Focus Group Discussion (FGD)}

FGDs will be held to enrich the data obtained through the previous methods.

\subsubsection{Data Analyze Method}

The collected data will be compiled for reduction, display, verification, and conclusion. As a tool for carrying out this process, the researcher will use machine learning. The data that has been collected will be coded, and cases will be created. Furthermore, it will be studied through the creation of matrix frameworks and clustering. The parameters for monitoring and assessment of digital transformation in higher education are as follows.

a. Organization and strategy

The Organization and strategy section include strategic plans developed in universities, both short and long term.

b. IT Capabilities

This section includes IT skills, IT infrastructure, IT organizations, and IT security issues.

c. Digital Academic Processes

This discussion includes student registration, academic or course management, scheduling, and student activity management.

d. Digital Research and Transfer

The following sections cover research proposal submission, review, reporting, management of data generated in research.

e. Digital infrastructure and resource management

This discussion includes human resource management, campus infrastructure management, and inventory management.

f. Digital marketing and relationship management This discussion includes tracer study, research partners, academic partners, companies for the internship, website quality.

The methodology of this research is shown as shown in Figure 1, which consists of User Input Data, Collect Data, Recording, Extract and Upload Data, Data Cluster, Data Cleaning, Clustered Index, Process Data for Machine Learning Based On Assessment, Process Data for Machine Learning Based On Assessment,

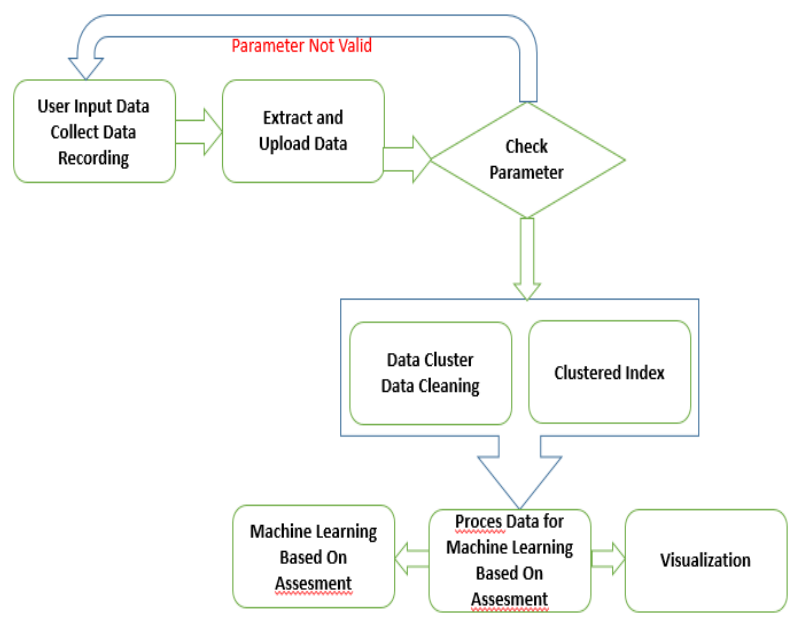

Figure 1 Monitoring and Assessment Based on Machine Learning

Machine Learning Based On Assessment and Monitoring, and Visualization.

a. User Input Data, Collect Data, Recording The user enters the parameters used in the following research. The parameters used include the strategic plan of the research object. Strategic plan used from the University of Brawijaya and State Islamic University of Maulana Malik Ibrahim Malang. The difference between the two universities in terms of scientific integration because at State Islamic University of Maulana Malik Ibrahim, there is the integration of science and Islam and vice versa at the University of Brawijaya only applies the scientific side of the general field.

b. Extract and Upload Data

The parameters used are extracted data in the form of special encoding. The next step is to upload the data and extract the data thoroughly using certain tools.

c. Data Cluster, Data Cleaning

Parameter grouping is done by determining the likeness of each data. Every public and private college implements Tri Dharma Higher Education. The Tri Dharma element of universities is grouped according to the specified cluster.

d. Clustered Index

The grouping of test data used is aimed at facilitating the identification of the parameters used. Indexing is done based on a previously defined code.

e. Process Data for Machine Learning Based on Assessment

The assessment made from both parameters is carried out thoroughly based on each test data that has been determined. The test results are carried out sequentially according to the necessary needs. 
f. Machine Learning Based on Assessment and Monitoring

The method used in the monitoring and assessment process is based on the results of tests based on machine learning.

g. Visualization

Recommended results from tests conducted based on the use of identified parameters. Dynamic monitoring and assessment are based on using a machine learning approach. Visualization results can be shown that assessment and monitoring parameters can degenerate automatically when determining the type of college selected.

\section{RESULTS AND DISCUSSION}

The parameters performed from both research objects can be indicated by the identification of the parameter used. Table 1 shows the parameters used from both colleges that have different characteristics. State Islamic University of Maulana Malik Ibrahim Malang has now become one of the universities with BLU status and was once promoted by the Ministry of Religion to become a world-class university. Also, to further enhance its role in national development has been proclaimed the ideals at State Islamic University of Maulana Malik Ibrahim Malang into the center of excellence and the center of
Islamic civilization as a step to implement the teachings of Islam as a mercy for the universe. Therefore, future development needs to be directed to regional recognition and reputation with autonomous status (PTN-BH). Based on the direction of this development, State Islamic University of Maulana Malik Ibrahim Malang has high competitiveness and can compete healthily with other universities in the world. Efforts to get to the University with Regional Recognition and Reputation.

The indicators achieved at the International Recognition and Reputation stage are as follows.

1. Modern campus with Islamic leadership and governance system international recognition

2. An infrastructure capable of carrying out various academic and non-academic activities and international services on land above $100 \mathrm{Ha}$

3. The Mahad system is to be occupied by Indonesian students, and cross-border countries with a distinctive and measurable Islamic character education with the capacity to Ma'had reached 7000 students

4. Questionable and modern services for the services of all stakeholders including cross-border stakeholders

5. The development of an effective and efficient governance system through accountable, credible, transparent, responsible, and fair

6. The development of integrated madrassas to

Table 1. Parameters used based on the strategic plan of the Institutional Establishment and Academic Reinforcement stage at the State Islamic University of Maulana Malik Ibrahim

\begin{tabular}{|l|l|}
\hline Code & \multicolumn{1}{|c|}{ Description } \\
\hline M01 & The construction of adequate infrastructure for offices at both the university and faculty level \\
\hline M02 & The construction of adequate infrastructure for ma'had that can accommodate 3000 students \\
\hline M03 & $\begin{array}{l}\text { The construction of adequate infrastructure for lecture activities, activities in laboratories, workshops, } \\
\text { and studios }\end{array}$ \\
\hline M04 & The construction of adequate infrastructure for student activities, body, and art \\
\hline M05 & The awakening of comfortable service rooms \\
\hline M06 & The awakening of a good governance system throughout the university \\
\hline M07 & $\begin{array}{l}\text { Establishment of a credible, accountable, effective, based on a strong culture derived from Islamic } \\
\text { values }\end{array}$ \\
\hline M08 & Establishment of a reliable leadership and management system \\
\hline M09 & $\begin{array}{l}\text { The realization of curriculum that leads to the vision, has competence and have the right body of } \\
\text { knowledge }\end{array}$ \\
\hline M10 & The establishment of a well-organized academic system in learning, research and community service \\
\hline M11 & The growth of academic atmosphere and declining political nuance throughout the university \\
\hline M12 & The realization of information systems based on Information Technology \\
\hline M13 & Study programs accredited by BAN-PT \\
\hline M14 & $\begin{array}{l}\text { Internationalizing institutions and courses } \\
\text { webometric versions }\end{array}$ \\
\hline M15 & $\begin{array}{l}\text { Building a Curriculum that has international competencies with peculiarities integration of science } \\
\text { and Ism as evidenced by a review of curriculum experts on in higher education ranked below } 1000\end{array}$ \\
\hline
\end{tabular}


international standard madrassas

7. Proper and fair remuneration system with minimum income of education personnel $150 \%$ of regional minimum wage Malang city per month

8. Cooperation with foreign institutions that are functional and mutually profitable

9. The awakening of a cross-border promotion system through various media and activities planned promotions

10. The growth of various academic and non-academic activities conducted by UIN Maulana Malik Ibrahim Malang with Foreign institutions

11. The growing number of foreign students from all over the world

12. A growing number of lecturers and educational personnel who can speak English or Arabic are implemented in lectures and services

13. The growth of international classes attended by cross-border students and taught by $10 \%$ to $20 \%$ of lecturers from Foreign Universities who have a ranking in under 500 versions of Webometric

14. The development of courses in medical and scientific Health

15. $80 \%$ A accredited Study Program by BAN-PT and $50 \%$ accredited by AUN-QA or International Professional Association

16. Graduate students make up $50 \%$ of all university students

17. The curriculum that has international competencies with the peculiarities of science integration and Islam as evidenced by a review of curriculum experts on similar sciences in colleges rank below 500 versions of Webometric

18. Development of IT-based service systems and elearning systems for learning in special fields

19. The growth of lecturers who teach/become speakers in universities ranked below 500 versions of Web metric

20. The growing number of researches with grants from Abroad or research presented in scientific activities at the Universities ranking below 500 Web metric versions

21. The amount and a study in higher education between $10-15 \%$ of and a whole in higher education

22. The growing number of HAKI, especially related to the domain of science integration and Islam

23. The growth of intellectual activities implemented in the region national or regional Asia with funding of at least IDR 10,000,000,000 per year

24. The growing number of students who can play a role in jobs International

25. The amount of funding sourced from PNBP reaches IDR 70,000,000,000 per Year

State Islamic University of Maulana Malik Ibrahim Malang has established herself towards Regional Recognition and Reputation in its strategic planning. Based on the study of strategic issues that have been done, so to strengthen the policy at State Islamic University of Maulana Malik Ibrahim Malang in 2018-
2022 needs to be carried out internationalization activities of institutions and study programs, build a curriculum that has international competencies with the peculiarities of the integration of science and Islam, and develop various academic and non-academic activities with foreign institutions. The following parameters are used in dynamic assessment and monitoring testing.

The parameters used at the University of Brawijaya are categorized as follows.

1. Improving the quality of education

2. Improvement of research quality and community service

3. Improvement of student and alumni quality

4. Improvement of institutional quality and cooperation

A. Improving access and equalization of education

1. Improved access and quality of prospective students

2. Improvement of the quality of the study program

3. Opening of a new course

4. Improvement of Student/Lecturer Ratio

5. Improvement of PBM facilities and infrastructure

6. Completion of the construction of Education Hospital

7. Development of UB Campus outside the main campus

8. Development of UB Campus facilities and infrastructure to Green Campus

9. Development of airy laboratory infrastructure and UB technopark

10. Improved educational resources and media

11. Improvement of lecturer quality

12. Development of entrepreneurial education

13. Vocational education development

14. Strengthening the implementation of KBK curriculum with KKNI standard

15. Improved competitiveness of graduates

16. Improved International Competitiveness

17. Improved information systems for postgraduate academic services

18. Improvement of lecturer quality

19. Professor acceleration

20. Improved PBM process efficiency

21. Implementation of Remote Education (PJJ)

B. Improving the quality of research and community service

1. Increased resource capacity for research

2. Institutional capacity building

3. Coaching and Improving the Quality of Research

4. Coaching and Improving the Quality of Research

5. Development of multi-discipline research with a new paradigm

6. Increased domestic research cooperation

7. Increase in number of Publications 
8. Development of accredited national journal publishers

9. Improved publication quality

10. Increase in international publications

11. Growth and Development of International Level Research Center

12. Growth and development of international Journal Publishers

13. Development of Cooperation with international institutions in the field of Research

14. Increased value for research

15. Increase in the number of community service activities

16. Increase in societal activities

17. Community entrepreneurship development

18. Development of effective science and social review activities

C. Improvement of student and alumni quality

1. Increase in the number of scholarship students

2. Improved student achievement

3. Imaging of student activities internationally

4. Student career development

5. Establishment of Student Identity

6. Improving student innovation and creativity

7. Improvement of student entrepreneurial spirit

8. Improved competitiveness of graduates

9. Increasing the role of activities in the international

10. Increased student participation in international Professional Associations

11. Improvement of student facilities and infrastructure

12. Establishment of innovation and creativity of students

D. Improvement of institutional quality and cooperation

1. Improvement of quality and quantity of capacity

2. Increased equalization of higher education opportunities for Community

3. Development of diversity and access to educational services

4. Increased budget independence from cooperation and business units

5. Development of Entrepreneurial University supporting services unit

6. Development into a Law University

7. Development of Quality Accreditation of Institutions

8. Increased Competitiveness at the International level

9. Increased international cooperation for education with sister models

10. university in the form of lecturer and/or student exchange, double degree, sandwich programs, or other programs that are representative

11. Increased funding from corporate social responsibility (CSR) companies

12. State-owned enterprises/private enterprises/PMA
Table 2. Result of Optimization

\begin{tabular}{|l|r|}
\hline \multicolumn{1}{|c|}{ Parameter } & Result of Optimalization \\
\hline UINM01 - UINM015 & 4,466666667 \\
\hline UINN01 - UINN25 & 4,6 \\
\hline UBA01 - UBA21 & 4,571428571 \\
\hline UBB01 - UBB18 & 4,555555556 \\
\hline UBC01 - UBC12 & 4,583333333 \\
\hline UBD01 - UBD13 & 4,615384615 \\
\hline
\end{tabular}

13. Increased international research funding from international agencies.

The parameters used can be shown as follows.
a. UINM01 - UINM015
b. UINN01 - UINN25
c. UBA01 - UBA21
d. UBB01 - UBB18
e. UBC01 - UBC12
f. UBD01 - UBD13

The results obtained in the study are shown as follows. The parameters in determining to model on Dynamic Monitoring and Assessment in both higher universities are shown in Figure 2. The measurement results are done randomly from the strategic plan at higher universities.

The following research shows that dynamic monitoring and assessment based on machine learning can model digital transformation in college. The results obtained from each parameter used in system testing have an average level of optimization in the monitoring and assessment process. In testing, the method showed that it yielded an average of $78 \%$. This indicates that the accuracy of machine learning usage can implement dynamic monitoring and assessment in digital transformation in universities. Future research can add comparison methods to produce a better level of accuracy.

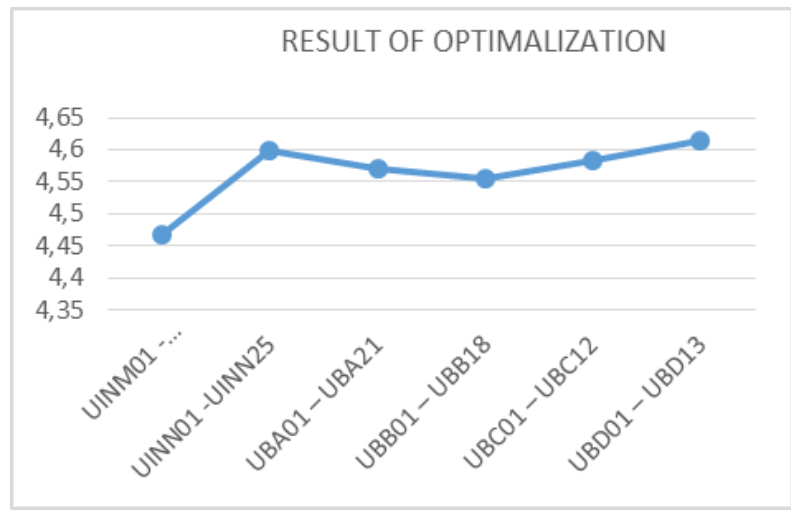

Figure 2. The Visualization of Result of Optimization 


\section{CONCLUSION}

The following research uses machine learning in monitoring and assessment in universities. The parameters that have been done are thorough identification of the strategic plan in the college. The results showed that modelling in monitoring and assessment could be done in higher universities with parameters that have been used capable of producing a good level of accuracy. It can be done based on the strategic plan set out in the college using machine learning. A comparative method is required in subsequent research to improve the level of accuracy.

\section{ACKNOWLEDGMENTS}

Thanks to the Research and Community Service Institute at the Islamic State University of Maulana Malik Ibrahim, who has provided support in research and publication on research activities.

\section{REFERENCES}

[1] X. Xu, Y. Wang, and S. Yu, "Teaching performance evaluation in smart campus," IEEE Access, vol. 6, pp. 77754-77766, 2018.

[2] M. Mohammadi, A. Al-Fuqaha, S. Sorour, and M. Guizani, "Deep learning for IoT big data and streaming analytics: A survey," IEEE Commun. Surv. Tutorials, vol. 20, no. 4, pp. 2923-2960, 2018.

[3] L. M. Camarinha-Matos, R. Fornasiero, J. Ramezani, and F. Ferrada, "Collaborative networks: A pillar of digital transformation," Appl. Sci., vol. 9, no. 24, 2019.

[4] S. K. Howell, H. Wicaksono, B. Yuce, K. McGlinn, and Y. Rezgui, "User Centered NeuroFuzzy Energy Management through Semantic-
Based Optimization," IEEE Trans. Cybern., vol. 49, no. 9, pp. 3278-3292, 2019.

[5] P. Matkovic, P. Tumbas, M. Maric, and L. Rakovic, "Digital Transformation of Research Process At Higher Education Institutions," INTED2018 Proc., vol. 1, no. March, pp. $9467-$ 9472, 2018.

[6] K. G. Bakieva and S. K. Muradkasimova, "Enhancing ICT Technologies in Teaching, Learning and Assessment of foreign languages in Uzbekistan.," Int. Conf. Inf. Sci. Commun. Technol. Appl. Trends Oppor. ICISCT 2019, pp. 1-3, 2019.

[7] E. Abad-Segura, M. D. González-Zamar, J. C. Infante-Moro, and G. R. García, "Sustainable management of digital transformation in higher education: Global research trends," Sustain., vol. 12 , no. 5,2020

[8] H. Vargas et al., "Automated assessment and monitoring support for competency-based courses," IEEE Access, vol. 7, pp. 41043-41051, 2019.

[9] V. Ahmed, K. A. Alnaaj, and S. Saboor, "An investigation into stakeholders' perception of smart campus criteria: The American University of Sharjah as a case study," Sustain., vol. 12, no. 12, 2020 .

[10] Y. Irawan, S. Muzid, N. Susanti, and R. Setiawan, "System Testing using Black Box Testing Equivalence Partitioning (Case Study at Garbage Bank Management Information System on Karya Sentosa)," pp. 1-7, 2019. 